\title{
Nutritional survey of Bangladeshi children aged under 5 years in the London borough of Tower Hamlets
}

\author{
R J HARRIS, D ARMSTRONG, R ALI, AND A LOYNES \\ Children's Department, The London Hospital; Community Child Health Services, Tower Hamlets Health \\ District, London
}

SUMMARY The main deficiencies in the diet of Bangladeshi infants and children are vitamin D, iron, and later, calories. Protein intake is a little low in some, but in general is satisfactory. Calcium and vitamin $C$ intakes are adequate. The proportions of food are often inappropriate, mainly because of a high carbohydrate intake. Weaning tends to be late, with predominant milk drinking, even into the second year of life. Convenience baby foods, containing mainly carbohydrate are the major components of the diet until well into the second and third years of life, without the conversion to family food seen in white children. Vitamin D is given to fewer than half the children. It may be given to fewer still if the observation that bottles were often unopened is true for many families.

The London Borough of Tower Hamlets is a deprived inner city area with a large immigrant community, consisting mainly of families from Bangladesh. The paediatricians and dietitians at The London Hospital and Queen Elizabeth Hospital for Children, as well as the health visitors in the Spitalfields and St George areas of Tower Hamlets, where the Bangladeshi immigrants are concentrated, were concerned by the number of Bangladeshi infants and chili,en presenting to hospital outpatient departments and community infant welfare clinics with nutritional problems. The most common problems were rickets, iron deficiency anaemia, gastroenteritis, and difficulties with weaning. Such problems are not rare among Asians in Great Britain, ${ }^{1}$ but as there are more Bangladeshi families in Tower Hamlets than in the rest of the country, it was decided to carry out a nutritional survey of a sample of Bangladeshi mothers and children to assess daily food intake. The findings of this nutritional survey are reported.

\section{Materials and methods}

The aim of the study was primarily to assess the children's vitamin D intakes, but dietary intakes of iron, protein, calcium, vitamin $\mathrm{C}$, and energy were calculated too.

A questionnaire was devised to gain information about feeding history, cooking facilities, home conditions, and daily food and drink intake. The questionnaire was completed in the homes of families by a Bangladeshi nurse employed for this purpose. The families were chosen at random by health visitors during a 6-month period. As ages ranged from 6 months to 4 years 9 months, the children were subdivided into the following groups: group 1, 6 months to 1 year; group 2, 1-2 years; group 3, 2-3 years; and group 4, 3-5 years.

Information on the child's diet and feeding pattern was obtained using the quantitative 7-day diet history method. The estimation of quantities was based on household measures, and this should be taken into account when considering the results.

The food values of McCance and Widdowson ${ }^{2}$ together with information obtained from the manufacturers on dried milks and infant foods were used for the calculations.

\section{Results}

Of the total sample, $95 \%(168 / 177)$ were on fortified breast milk from birth, and $5 \%(8 / 177)$ on fortified dried milks. In one case details of the milk were not known. This compares favourably with the report Breast feeding ${ }^{3}$ in which $51 \%$ of the babies in the sample were put to the breast.

Of the babies started on breast milk, 125 had had breast milk only and 43 had had breast milk and 


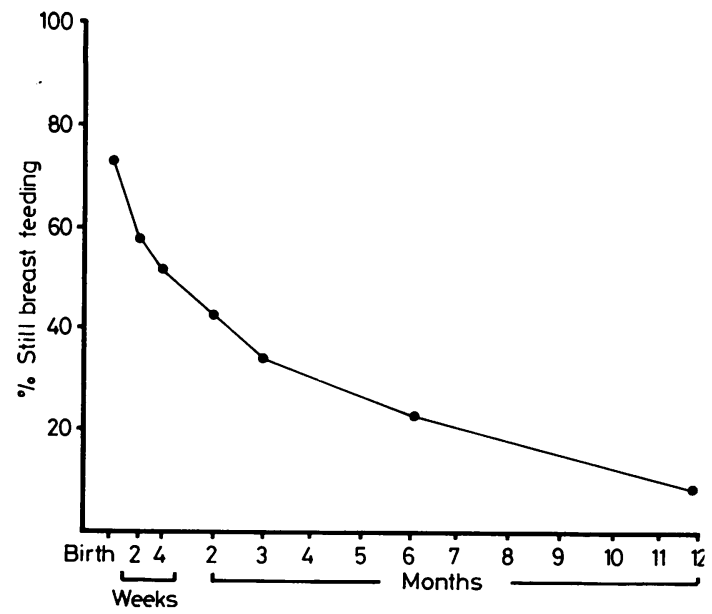

Fig. 1 Proportion of babies in total sample $(n=176)$ started on breast milk only and continuing with breast milk only (that is no other milk given) at ages up to 12 months.

complement of fortified dried milks. Fig. 1 illustrates the proportion of babies in the total sample started on breast milk only and continuing with breast milk only. There were 3 children at age 2 years who, according to their mothers, were still receiving only breast milk.

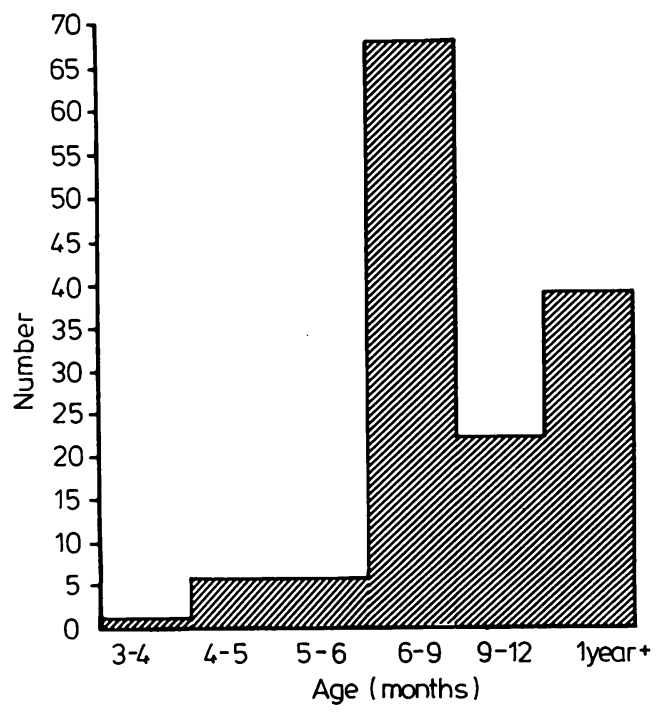

Fig. 2 Age at starting cows' milk $\left(n=142^{*}\right)$. * In 11 cases the age at which 'cows' milk was started was not known, and in 24 cases babies were still on breast milk or fortified milk.

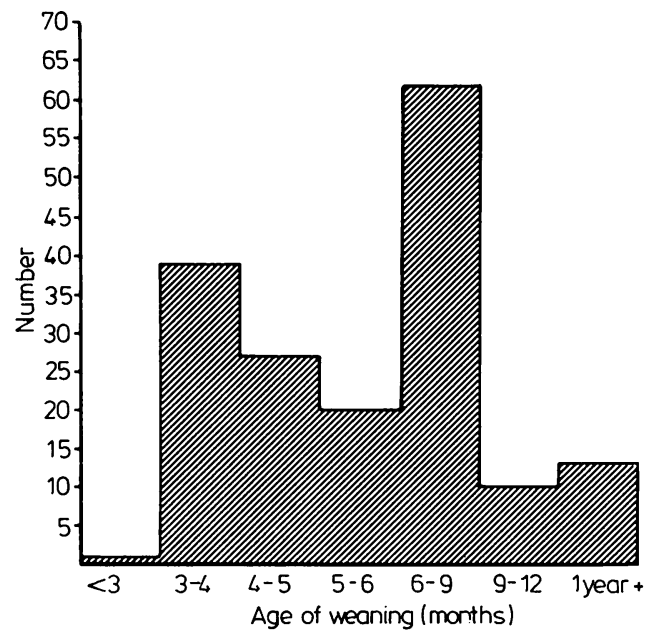

Fig. 3 Age at weaning $\left(n=172^{*}\right)$.

*In 5 cases the age at weaning was not known.

Fortified dried milk had been given to 141 of the infants at some time; in 3 cases details were not known, and the remaining 33 infants were either still on breast milk or had been breast fed before going straight on to cows' milk. The age at which children started cows' milk is shown in Fig. 2.

Solids (Fig. 3) had been introduced at between ages 2 months and 2 years. There was a tendency for later weaning to occur if mothers had spent only a short time in this country $(2.7$ years for weaning at $>12$ months, compared with 4.4 years for weaning at 3 to 4 months).

The main types of food eaten by the children in the four groups are shown in Table 1. Although it was reported that 'family' foods were being taken, 4 of the children in group 1 and 14 of the children in group 2 were receiving fairly small quantities-that is 1-3 teaspoonfuls a day. Convenience baby foods were popular, especially among children in group 1 , (taken by $95 \%$ ). Of the total sample, $41 \%$ were on vitamin supplements. Of the children receiving vitamin supplementation, the dosages ranged from 1 to 12 drops a day (maximum recommended: 5 drops). The mean daily vitamin $D$ intakes from food, calculated from the diet histories taken and the mean daily vitamin $\mathbf{D}$ intakes, including vitamin $\mathbf{D}$ supplements which the mothers claimed to be giving, are shown in Table 2 . Forty one $(84 \%)$, sixty one $(86 \%)$, twenty two $(96 \%)$, and all respectively of groups $1,2,3$, and 4 were receiving less than the UK recommended daily amounts ${ }^{4}$ from food sources alone. With vitamin supplements included, twenty eight $(57 \%)$, fifty $(70 \%)$ and 
Table 1 Types of food eaten

\begin{tabular}{|c|c|c|c|c|c|c|c|c|}
\hline \multirow[t]{3}{*}{ Types of food } & \multicolumn{8}{|c|}{ Group } \\
\hline & \multicolumn{2}{|c|}{$1(n=60)$} & \multicolumn{2}{|c|}{$2(n=76)$} & \multicolumn{2}{|c|}{$3(n=23)$} & \multicolumn{2}{|c|}{$4(n=18)$} \\
\hline & $N o$ & $(\%)$ & $N o$ & $(\%)$ & No & $(\%)$ & No & $(\%)$ \\
\hline $\begin{array}{l}\text { Fortified cereals and rusks } \\
\text { Convenience baby foods }\end{array}$ & 43 & (72) & 44 & $(58)$ & 6 & (26) & 1 & (6) \\
\hline All kinds & 57 & $(95)$ & 42 & $(55)$ & 4 & (17) & 1 & (6) \\
\hline Savoury & 20 & (33) & 19 & (25) & 2 & (9) & 1 & (6) \\
\hline Sweet & 37 & $(62)$ & 28 & (37) & 3 & (13) & $\mathbf{0}$ & \\
\hline Eggs & 8 & (13) & 47 & (62) & 17 & (74) & 11 & (61) \\
\hline Oily fish & 0 & & 13 & (17) & 6 & (26) & 7 & (39) \\
\hline Family foods* & 5 & (8) & 56 & (74) & 21 & (91) & 18 & (100) \\
\hline Ribena/Delrosa & 28 & (47) & 40 & (53) & 9 & (39) & 16 & (89) \\
\hline Cakes/biscuits & 3 & (5) & 48 & (63) & 19 & (83) & 18 & (100) \\
\hline Sweets/chocolate/crisps/drinks $\dagger$ & 3 & (5) & 51 & (67) & 21 & (91) & 18 & (100) \\
\hline
\end{tabular}

*Rice, meat, fish, or chicken curries, vegetables, and occasionally dahl were the typical family foods. †Drinks such as squashes, lemonade, and Pepsi.

Table 2 Mean daily vitamin $D(\mu g)$ intake with and without vitamin supplements

\begin{tabular}{|c|c|c|c|c|}
\hline & \multicolumn{4}{|l|}{ Group } \\
\hline & $I(n=49)^{*}$ & $2(n=7 I)^{*}$ & $3(n=23)$ & $4(n=16)^{*}$ \\
\hline $\begin{array}{l}\text { Without supplements } \\
\text { Range } \\
\text { With supplements } \\
\text { Range }\end{array}$ & $\begin{array}{l}6 \cdot 1 \pm 3 \cdot 8 \\
0 \cdot 4-15 \cdot 9 \\
9 \cdot 8 \pm 5 \cdot 9 \\
0 \cdot 4-26 \cdot 4\end{array}$ & $\begin{array}{l}4 \cdot 5 \pm 4 \cdot 6 \\
0 \cdot 1-17 \cdot 3 \\
8 \cdot 1 \pm 5 \cdot 8 \\
0 \cdot 1-20 \cdot 4\end{array}$ & $\begin{array}{l}2 \cdot 3 \pm 2 \cdot 7 \\
0 \cdot 3-10 \cdot 1 \\
6 \cdot 0 \pm 6 \cdot 3 \\
0 \cdot 3-18 \cdot 3\end{array}$ & $\begin{array}{l}1 \cdot 4 \pm 1 \cdot 7 \\
0 \cdot 2-7 \cdot 2 \\
\text { None }\end{array}$ \\
\hline
\end{tabular}

* 18 of the dietary histories omitted because of lack of information.

Table 3 Mean daily intake of cows' milk in the total sample $(n=159) *$

\begin{tabular}{lllll}
\hline Group & & & & \\
\hline & $\begin{array}{l}1 \\
(n=38) *\end{array}$ & $\begin{array}{l}2 \\
(n=64) \dagger\end{array}$ & $\begin{array}{l}3 \\
(n=23)\end{array}$ & $\begin{array}{l}4 \\
(n=16)\end{array}$ \\
\hline $\begin{array}{l}\text { Mean milk intake } \\
\text { (f oz) }\end{array}$ & 26 & 26 & 24 & 12 \\
Range & $5-60$ & $5-60$ & $5-40$ & $3-30$ \\
\hline
\end{tabular}

*11 on fortified/breast milk, $\nmid 3$ on fortified milks and 4 reported as not receiving any milk, $\$ 18$ of the dietary histories omitted because of lack of information.

sixteen $(70 \%)$ respectively of groups 1,2 , and 3 were receiving less than the recommended daily amounts.

The mean daily intakes of other nutrients, calculated from the diet histories, are shown in Table 3. Table 4 shows the mean intake and range of intakes for cows' milk.

In groups 1, 2, 3, and 4 twenty two ( $45 \%)$, forty seven $(66 \%)$, fifteen $(65 \%)$, and twelve $(75 \%)$ respectively did not meet the UK recommended dietary amount for energy. For protein, twelve $(24 \%)$, twenty $(28 \%)$, five $(22 \%)$, and one $(6 \%)$ respectively did not meet the recommended dietary amount.
The major contributors to the total iron intakes were fortified cereals and rusks. For groups 1, 2, 3, and 4 , forty $(82 \%)$, sixty one $(86 \%)$, twenty two $(96 \%)$, and all, respectively were receiving less than the UK recommended daily amount from food sources other than fortified cereals and rusks. With fortified cereals and rusks included, twenty one $(43 \%)$, forty two $(59 \%)$, seventeen $(74 \%)$, and all, respectively of each group were receiving less than the recommended daily amount.

Vitamin C intakes were generally high as a result of the combined intakes of Ribena/Delrosa and vitamin supplements as well as oranges and mangoes. In the total sample of 159 , ten $(6 \%)$ of the children were receiving less than the UK recommended daily amount. The diet of these children was one of cows' milk, fortified cereals, and convenience baby foods.

Thirty two $(20 \%)$ children did not receive the recommended daily amount of calcium. Four of these were receiving no milk at all, and twenty eight were receiving only between 3 and 13 ounces a day. However, calcium intake is probably less of a problem than this, as the local water in Tower Hamlets has an average calcium content of 117 $\mathrm{mg} / \mathrm{l}$. Calcium intake from this source has not been included in the calculations. 
Table 4 Mean daily nutrient intake (range) and recommended daily amounts in the total sample $(n=159) *$

\begin{tabular}{|c|c|c|c|c|c|}
\hline \multirow[t]{2}{*}{ Group } & \multicolumn{5}{|c|}{ Daily nutrients } \\
\hline & $\begin{array}{l}\text { Energy } \\
(K \text { cal })\end{array}$ & $\begin{array}{l}\text { Protein } \\
(\mathrm{g})\end{array}$ & $\begin{array}{l}\text { Calcium } \\
(m g)\end{array}$ & $\begin{array}{l}\text { Iron } \\
\text { (mg) }\end{array}$ & $\begin{array}{l}\text { Vitamin } C \\
(\mathrm{mg})\end{array}$ \\
\hline $1(n=49)$ & $\begin{array}{l}931 \pm 315 \\
(328-1703)\end{array}$ & $\begin{array}{l}31 \pm 14 \\
(7-71)\end{array}$ & $\begin{array}{c}1022 \pm 470 \\
(224-2433)\end{array}$ & $\begin{array}{l}9 \cdot 6 \pm 5 \\
(1 \cdot 5-21)\end{array}$ & $\begin{array}{l}117 \pm 97 \\
(5-373)\end{array}$ \\
\hline RDA & 895 & 22 & 600 & 6 & 20 \\
\hline $2(n=71)$ & $\begin{array}{l}1136 \pm 396 \\
(571-2256)\end{array}$ & $\begin{array}{l}43 \pm 17 \\
(10-93)\end{array}$ & $\begin{array}{l}1091 \pm 539 \\
(115-2598)\end{array}$ & $\begin{array}{l}9 \cdot 4 \pm 6 \\
(1 \cdot 3-25)\end{array}$ & $\begin{array}{l}107 \pm 89 \\
(6-401)\end{array}$ \\
\hline RDA & 1250 & 33 & 600 & 7 & 20 \\
\hline $3(n=23)$ & $\begin{array}{c}1331 \pm 393 \\
(666-2134)\end{array}$ & $\begin{array}{l}50 \pm 15 \\
(26-80)\end{array}$ & $\begin{array}{l}1063 \pm 511 \\
(308-1902)\end{array}$ & $\begin{array}{l}7 \cdot 0 \pm 4 \\
(2 \cdot 4-17)\end{array}$ & $\begin{array}{l}112 \pm 96 \\
(27-417)\end{array}$ \\
\hline RDA & 1440 & & 600 & 7.5 & \\
\hline $4(n=16)$ & $\begin{array}{l}1288 \pm 244 \\
(759-1689)\end{array}$ & $\begin{array}{l}50 \pm 11 \\
(39-73)\end{array}$ & $\begin{array}{l}605 \pm 373 \\
(219-1493)\end{array}$ & $\begin{array}{l}6 \cdot 0 \pm 2 \\
(3 \cdot 6-9)\end{array}$ & $\begin{array}{l}64 \pm 38 \\
(22-173)\end{array}$ \\
\hline RDA & 1530 & 38 & 600 & 9 & \\
\hline
\end{tabular}

*18 of the dietary histories omitted because of lack of information. RDA = recommended daily amount.

\section{Discussion}

In recent years, rickets has re-emerged as an appreciable problem in many inner urban areas where there is a high Asian immigrant population. ${ }^{36}$ In Tower Hamlets there is a large Bangladeshi community, and these people are the poorest and most deprived of the various Asian immigrant groups in this country. Between 12 and 15 new cases of rickets a year are seen in Tower Hamlets in toddlers, but there is iron deficiency anaemia as well as general weaning and nutritional problems. A survey of haemoglobin concentration is currently being carried out on the Bangladeshi in Tower Hamlets.

The dietary survey showed that the main deficiencies of intake were iron, vitamin $\mathrm{D}$, and energy, and that protein and calcium intakes were generally adequate.

The incidence of breast feeding was high, although it has been suggested that Asian women in this country do not breast feed. ${ }^{7}$ There is a tendency to breast feed for longer than most British women, as is the custom in Bangladesh. In the survey, three children were still being fully breast fed at age 2 years. Breast milk alone is an inadequate source of nutrition in this country being deficient in iron and possibly in vitamin $\mathrm{D}$. Most of the children with rickets in Tower Hamlets have had prolonged breast feeding with no added vitamins.

The introduction of fresh cows' milk is often delayed in Bangladeshi infants who are being artificially fed, $28 \%$ still not receiving it by age 12 months. However, there may be an advantage in prolonged feeding of proprietary milk preparations, as these are fortified with iron and vitamins.

By age 6 months $87 \%$ of the infants were receiving some form of solids. There were, however, a few children to whom solids were introduced very late. If solids are not introduced by 8-9 months there may be increasing difficulties in establishing full mixed feeding, and this could explain some of the weaning difficulties. There was a tendency for later weaning if the mother had been in England for a fairly short time, a trend that has been noticed elsewhere. ${ }^{17}$ Late weaning is normal in Bangladesh, chiefly because it is difficult to obtain appropriate food. The weaning process used in the West was not adopted by Bangladeshi families, since none of the diet histories reported the use of pureed (or liquidised) minced, or chopped foods. Convenience baby foods were being used, mainly because medical workers recommend them as they are sterile. The most commonly given convenience foods were the sweet varieties (for example egg custard, rice pudding, and various fruit desserts). This may be because the savoury types that include meat are non-halal. The sweet convenience foods are low in protein and iron. The use of convenience baby foods means that the infants are not getting used to adult types of food, and may explain why we are seeing 1,2 , and 3 year olds existing mainly on milk, cereals or rusks, and convenience baby foods. Although family food is given, the amounts are very small. The survey shows also that there is an almost universal intake of sweets, cakes, biscuits, chocolate, crisps, and sweetened drinks.

The combination of late weaning and a high carbohydrate intake can lead to two problems in particular. Firstly, a child fed on milk alone will not sustain adequate growth beyond infancy. ${ }^{1}$ This has been seen in Tower Hamlets, and both for boys and girls in the sample there was a slight reduction in the mean growth rate between ages 1 and 3 years. Secondly, children with a high carbohydrate intake become obese and tend to have a low protein intake. Although protein intake was considered adequate, $20.3 \%$ of the children were receiving less than the recommended daily amount. Such children eat a high carbohydrate diet. 
Iron deficiency anaemia is present in many Bangladeshi children because of the late introduction of iron rich foods. However, iron deficiency anaemia can occur in children receiving fortified cereals and rusks-whose dietary intake of iron from such sources is adequate. This presumably means that the iron of these cereals and rusks is not well absorbed. The rusk referred to in the diet histories has reduced metallic iron powder added (information obtained from the manufacturers) rather than the better absorbed iron salts (for example ferrous sulphate) which are added to the fortified milks.

Pasteurised or homogenised cows' milk contains little iron. It has also been shown that small, daily blood losses from the gastrointestinal tract occur in some infants fed on this milk. ${ }^{8}$ Although this small loss would not be important in a child eating iron containing foods, without them such blood losses may contribute to iron deficiency anaemia.

Vitamin D intake was reduced in many of the children. In rural Bangladesh there is more exposure to ultra-violet irradiation from the sun than there is in Tower Hamlets. In Tower Hamlets the children seldom leave the house. However, the figure of $41 \%$ claiming to be giving vitamin supplements to their infants may be an overestimate, as occasionally the Bangladeshi nurse found bottles of vitamins unopened in the house.
We thank Dr J A Walker-Smith and Miss B Lawrie, Queen Elizabeth Hospital for Sick Children, for advice.

The Spitalfields Project provided financial support.

\section{References}

1 Jivani SKM. The practice of infant feeding among Asian immigrants. Arch Dis Child 1978; 53: 69-73.

2 McCance RA. McCance and Widdowson's The composition of foods. Fourth revised edition. MRC Special Report No 297. London: HMSO, 1978.

3 Department of Health and Social Security Committee on Medical Aspects of Food Policy: Panel on Child Nutrition. Breast feeding. London: HMSO, 1979.

4 DHSS. Recommended daily amounts of food energy and nutrients for groups of people in the United Kingdom. Report on Health and Social Subjects No 15. London: HMSO, 1979.

5 Moncrieff MW, Lunt HRW, Arthur LJH. Nutritional reckets at puberty. Arch Dis Child 1973; 48: 221-4.

6 Goel KM, Sweet EM, Logan RW, Warren JM, Arneil GC, Shanks RA. Florid and subclinical rickets among immigrant children in Glasgow. Lancet 1976; i: 1141-5.

7 Evans N, Walpole IR, Qureshi MU, Memon MH, Everley Jones HW. Lack of breast feeding and early weaning in infants of Asian immigrants to Wolverhampton. Arch Dis Child 1978; 51 : 608-12.

8 Smith NJ, Rios E. Iron metabolism and iron deficiency in infancy and childhood. Adv Pediatr 1974; 21 : 239-80.

Correspondence to $\operatorname{Dr} \mathbf{R} \mathrm{J}$ Harris, Children's Department, The London Hospital, Whitechapel, London E1 1BB.

Received 24 January 1983

British Paediatric Association

Annual meetings

1984 10-14 April York University

1985 16-20 April York University

1986 15-19 April York University

1987 7-11 April York University 